[Agr. Biol. Chem., Vol. 32, No. 9, p. 1108 1114, 1968]

\title{
Chemical Structure of Piericidin A
}

\author{
Part VI. Stereochemistry
By Nobutaka Takahashi, Shigeo Yoshida, Akinori Suzuki and Saburo TAMURA \\ Department of Agricultural Chemistry, The University of Tokyo, Tokyo \\ Received March 23, 1968
}

\begin{abstract}
Absolute configurations of C-2 and C-3 in "Acid III" (IIa), a degradation product of piericidin A diacetate, was determined as $R$ and $S$, respectively. Consequently both C-9 and $\mathrm{G}-10$ in piericidin A were confirmed to have $S$ configurations. On the basis of UV and NMR specta, configurations of the double bonds in piericidin $\mathrm{A}$ were assigned as shown in Ia.
\end{abstract}

Piericidin $\mathrm{A}(\mathrm{PA})^{1,2}$ is a natural insecticide as well as a potent inhibitor ${ }^{3 /}$ of mitochondrial electron transport. In our preliminary report, ${ }^{41}$ $S$ configurations have been proposed to the assymetric centers, $\mathrm{C}-9$ and $\mathrm{C}-10$, contained in the compound. We wish to present the evidences in details which support this assignment and to discuss the configurations of the double bonds in PA.

Ozonolysis of PA diacetate afforded "Acid
III' (IIa) by fissions of the double bonds at $\mathrm{C}-7 \sim \mathrm{C}-8$ and $\mathrm{C}-11 \sim \mathrm{C}-12$. Since IIa possesses all assymetric centers originally contained in PA, elucidation of the stereochemistry of IIa was conducted.

The structure IIa previously assigned for "Acid III" was supported by the double resonance experiment as illustrated in Fig. 1. Furthermore, this formula was verified by the following synthesis shown in Scheme I. The<smiles>COc1nc(CC=CC(C)C=CCC(C)C(C)C(C)C(C)C(C)C)c(C)c(O)c1OC</smiles>

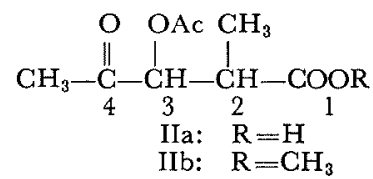

1) S. Tamura, N. Takahashi, S. Miyamoto, R. Mori, S. Suzuki and J. Nagatsu, Agr. Biol. Chem, 27, 576 (1963).

2) N. Takahashi, A. Suzuki and S. Tamura, $J$. Am. Chem. Soc., 87, 2066 (1965); N. Takahashi, A. Suzuki and S. Tamura, Agr. Biol. Chem., 30, 1 (1966).
3) C. Hall, M. Wu, F. L. Crane, N. Takahashi, S. Tamura and K. Folkers, Biochem. Biophys. Res. Commun., 25, 373 (1966).

4) N. Takahashi, A. Suzuki, Y. Kimura, S. Miyamoto and S. Tamura, Tetrahedron Letters, 1967, 1961. 


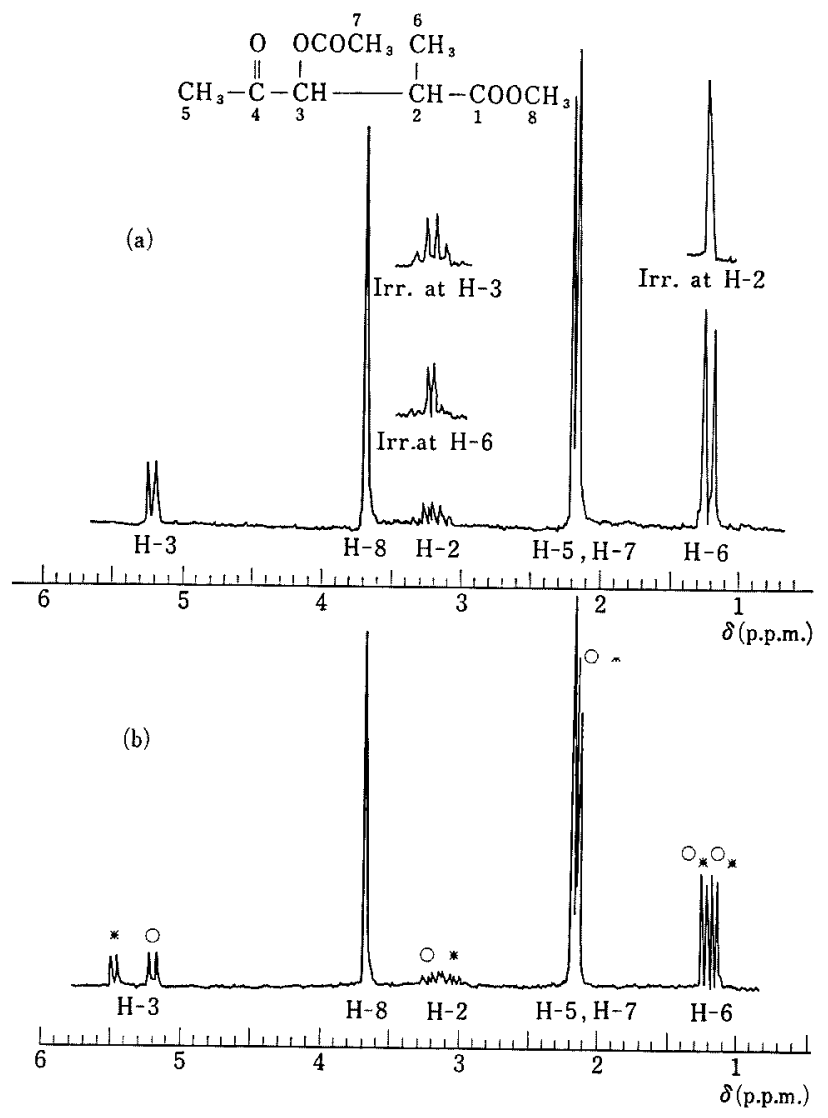

FIG. 1. NMR Spectra of the Natural and Synthetic IIb.

(a) The natural IIb

(b) The synthetic IIb

Signals due to the natural IIb

* Signals due to diastereomer of the natural IIb
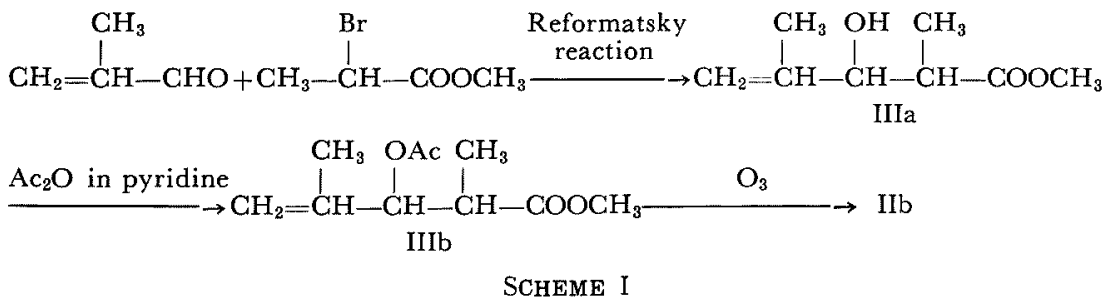

Reformatsky reaction between methacrolein lysed to give IIb. Although IIb thus syntheand methyl $\alpha$-bromopropionate and successive sized is a racemic mixture of diastereomers acetylation gave methyl 3-acetoxy-2,4-di- at $\mathrm{C}-2$ and $\mathrm{C}-3$, its IR spectrum was essentimethyl-4-pentenoate (IIIb), which was ozono- ally identical with that of IIb prepared from 
the natural IIa. However, the NMR spectrum of the synthetic IIb revealed additional signals besides those of the natural one as shown in Fig. I. Gas-liquid chromatography of the synthetic IIb on a succinate polyester column gave two peaks, while the natural IIb gave only one showing an identical retention time with that of the second peak of the former. This experiment indicates that racemization did not occur in the process of the preparation of IIa from PA. Hydrogenation of the natural IIa in acetic acid over Adams' catalyst gave a 1:1 mixture of a lactone (IV) and a hydroxy acid (V), while hydrogenation in methanol afforded a mixture of hydroxy acids containing only a trace amount of IV. The NMR spectrum of IV and its double resonance experiment (Fig. II) supported the proposed structure. The $50 \%$ yeild of $\mathrm{V}$ on hydrogenation of the natural IIa in acidic medium indicates that $\mathrm{V}$ would possess the configuration opposite to IV at $\mathrm{C}-4$ and could not form a $\gamma$-lactone ring due to large steric hindrance by all cis substituents. Now three stereochemical expressions for IV, namely, VI, VII and VIII or their enantiomeric structures, are possible. The difficulty of lactonization of $\mathrm{V}$ excludes the formula VIII, because the hydroxy acid epimeric to VIII at C-4 is expected to form readily a $\gamma$ lactone having all trans substituents.

Catalytic hydrogenation of the synthetic IIb in methanol gave a complex mixture, from which another $\gamma$-lactone (VII) with a different NMR spectrum from that of IV was isolated by silicic acid chromatography. The remarkable easiness of lactonization of hydrozy ester derived from the synthetic IIb leads to assign the structure VII with all trans substituents to the new lactone. The absence of VII in the hydrogenation products from the natural IIa indicates that VII must have been derived

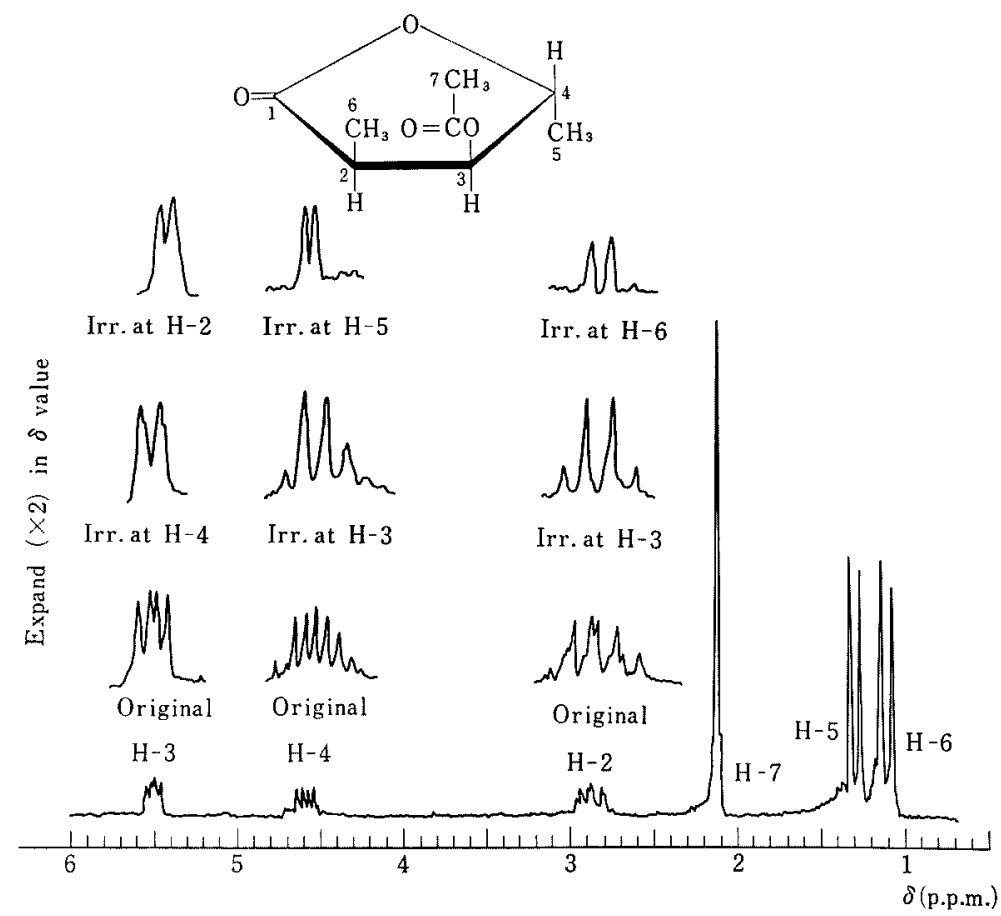

FIG. 2. NMR Spectrum of the Lactone (IV) and its Decoupling Study. 


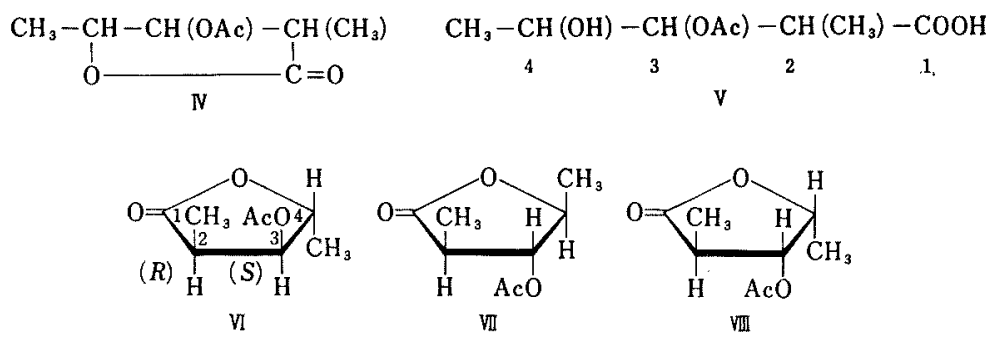

from the diastereomer of the natural IIa. Thus the structure VI was assigned to the lactone from the natural IIa. In the preliminary paper, " the coupling constants, $J_{\mathrm{H}-2 \cdot \mathrm{H} \cdot 3}=6$ cps (cis) and $J_{\mathrm{H} \cdot 3 \cdot \mathrm{H} \cdot 4}=3 \mathrm{cps}$ (trans), have been presented to support this stereochemical assignment. However, the NMR spectrum of VII with all trans substituents showed $J_{\mathrm{H}-2 \cdot \mathrm{H}-3}=5.5$ cps and $J_{\mathrm{H}-3 \cdot \mathrm{H}-4}=6.5 \mathrm{cps}$, suggesting the difficulty in applying the Karplus equation to the five membered ring systems. The evidence above cited allow to assign the relative configuration of $\mathrm{C}-2$ and $\mathrm{C}-3$ in the natural IIa as $S-R$ or $R-S$, and consequently $\mathrm{C}-9$ and $\mathrm{C}-10$ in $\mathrm{PA}$ as $R-R$ or $S-S$.

The remaning problem is to decide the absolute configuration for one of the assymetric centers by correlating it to the compound with any known absolute configuration. Lithium aluminum hydride reduction in boiling tetrahydrofuran of the natural IIb afforded a triol (IX), which was treated with two moles of methanesulfonyl chloride at $0^{\circ} \mathrm{C}$. From the reaction product dimethanesulfonate $(\mathrm{X})$ was isolated in a fairly good yield by silicic acid chromatography. $\mathrm{X}$ was reduced with lithium aluminum hydride in boiling ether to give an alcoholic product, which was characterized as a 3,5-dinitrobenzoate, $\operatorname{mp} 98 \sim 99^{\circ} \mathrm{C},[\alpha]_{D}^{16}=$ $+7.67^{\circ}$ The IR (in solution) and the NMR spectra of the benzoate were identical with those of the authentic 3,5-dinitrobenzoate of (土)-2-methyl-3-pentanol (XI). This indicates that two methanesulfonyl groups were introduced into $\mathrm{C}-2$ and $\mathrm{C}-4$ hydroxyl groups of IX, and the structure of the dimethanesulfonate was established as $\mathrm{X}$. Since the (-)-ester or (-)-alcohol have been correlated with L-glyceraldehyde by Büchi, ${ }^{51}$ the absolute configuration of $\mathrm{C}-3$ in the $(+)$-ester from the natural IIa must be $R$. Thus S-configurations were assigned to both $\mathrm{C}-9$ and $\mathrm{C}-10$ in PA from the stereochemical correlation of $\mathrm{PA}$ to (+)-2-methyl-3-pentanol (XI).

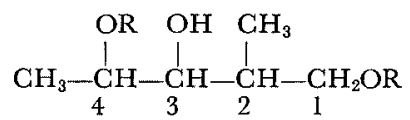

(S) $\quad(S)$

IX: $\quad \mathrm{R}=\mathrm{H}, \quad \mathrm{X}: \quad \mathrm{R}=\mathrm{SO}_{2} \mathrm{CH}_{3}$

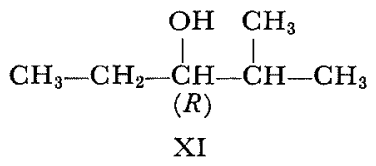

The very strong UV absorption of PA at $239 \mathrm{~m} \mu(\varepsilon 40000)$ gave a useful information for the configuration of the tetrasubstituted diene system. Even if the effect of the end absorptions due to the pyridine ring and two trisubstituted ethylenic double bonds is substracted, the intensity of this band would be about $\varepsilon 30000 \sim 35000$, suggesting the presence of transtrans conjugated system. This was further confirmed by the large coupling constant between $\mathrm{H}-4$ and $\mathrm{H}-5$ ( $16 \mathrm{cps}$ ) in its NMR spectrum.

The signal due to four allyl methyl groups of PA are observed in the range $\delta 1.5 \sim 1.8$ as illustrated in Fig. 3. Among them, the C-3 methyl attached to the conjugated diene system

5) G. Büchi, L. Crombie, P. J. Godin, J. S. Kaltenbronn, K. S. Siddalingaiah and A. A. Whiting, J. Chem. Soc., 1961, 2844. 


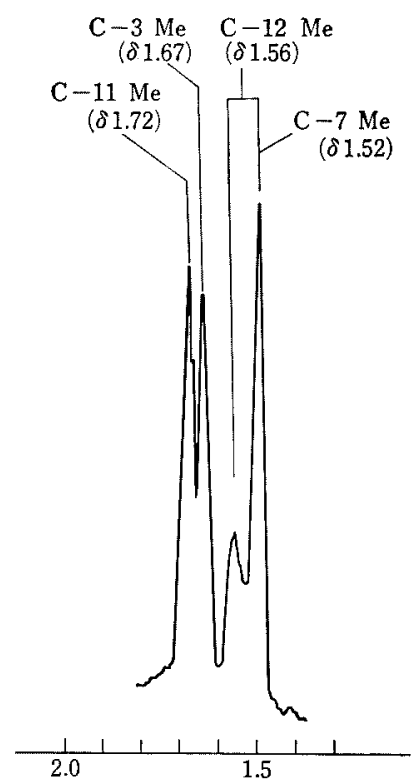

FIG. 3. NMR Spectrum of Piericidin $A$ in the Range of $\delta 1.5 \sim 1.8 \mathrm{ppm}$.

must resonate at the lowest field, $\delta$ 1.72. Besides the diene, PA contains two double bonds of Types $\mathrm{A}$ and $\mathrm{B}$.<smiles>CCC=C(C)CC</smiles>
Type A<smiles>CC=C(C)C(C)O</smiles>

Type B
In has been known that allyl methyls attached to cis and trans isomers of the Type $\mathrm{A}$ resonate at $\delta 1.66$ and $1.58,{ }^{6}$ respectively, while chemical shifts of allyl methyls of the Type B have not been reported yet. Then cis and trans isomers of 2-methyl-2-buten-1-ol were synthesized and their NMR spetra were compared. The chemical shifts of their allyl methyls are listed in Table I. Since the chemical shifts of $3 \mathrm{H}$ singlet at $\delta 1.67$ and $3 \mathrm{H}$ doublet at $o 1.55$ of PA are quite similar to those of the

6) R. B. Bates and D. M. Gale, J. Am. Chem. Soc., 82, 5749-5751 (1960); J.W.K. Burrell, R.F. Garwood, L. M. Jackman, E. Oskay and B. C. L. Weedon, J. Chem. Soc., Sect. C, 1966, 2144.
Table 1. Chemical Shift of Allyl Methyl GRoUPS IN 2-METHYL-2-BUTEN-1-OL

$$
\begin{aligned}
& \begin{array}{c}
\text { Configura- Chemical Shift } \\
\text { tion }
\end{array}
\end{aligned}
$$

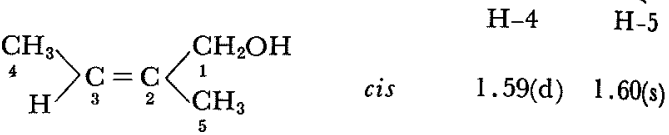

$$
\begin{aligned}
& { }_{\mathrm{H}}^{\mathrm{CH}_{3}}>\mathrm{C}=\mathrm{C}\left\langle\begin{array}{l}
\mathrm{CH}_{3} \\
\mathrm{CH}_{2} \mathrm{OH}
\end{array} \text { trans } 1.55(\mathrm{~d}) \quad 1.65(\mathrm{~s})\right. \\
& \text { Piericidin A } 1.52(\mathrm{~s}), \quad 1.55(\mathrm{~d}), 1.67(\mathrm{~s}), 1.72(\mathrm{~s})
\end{aligned}
$$

trans isomer, the former signal may be assigend to $\mathrm{C}-11$ methyl and the latter to $\mathrm{C}-12$ methyl. The remaining singlet at $\delta 1.52$ is reasonably assigned to $\mathrm{C}-7$ methyl in trans double bond. Thus the stereochemistry of PA is expressed as Ia.

\section{EXPERIMENTAL}

IR spectra were measured for liquid films on oily samples and nujol mull on crystals with a Koken DS 301 spectrometer. NMR spectra were determind for deuterochloroform solutions by a JNM-4H 100 spectrometer in 100 megacycle and chemical shifts were expressed in $\delta$-value (ppm) from tetramethylsilane as the internal standard. Double resonance experiments were performed by a JNM-SD-30 spin decoupler in deuterochloroform solutions. Retention times on gas-liquid chromatography were determined on a Shimazu Seisakusho GC-1B with a thermoconductivity detector in the following conditions: stainless column, $225 \mathrm{~mm} \times 4 \mathrm{~mm}$ i.d.; column packing, succinate polyester; column temperature, $210^{\circ} \mathrm{C}$; carrier gas, helium; flow rate, $80 \mathrm{ml} / \mathrm{min}$. Melting points were corrected.

Preparation of "Acid III" $(3(S)$-acetoxy-2 $(R)$ methyl-4-oxopentanoic acid, IIa) and its methyl ester. Acid III was prepared by the method described in the previous paper..$^{21} \mathrm{Mp} 97 \sim 98^{\circ} \mathrm{C}$. $[\alpha]_{D}^{18}=+6.4^{\circ}(c=2.5$, methanol $){ }^{*} \nu_{\max }^{\text {Nujol }}: 3320,1740$, $1718,1229,1190 \mathrm{~cm}^{-1}$ Treatment of Acid III with ethereal diazomethane gave the oily methyl ester. $\nu_{\text {max }}^{\text {Film: }} 1747,1240$ (broad), 1067, 1050, $1026 \mathrm{~cm}^{-1}$. It showed a peak at retention time $11.2 \mathrm{~min}$ on gasliquid chromatography. The NMR spectrum is shown in Fig. 1.

* The optical rotation datum reported previously for "Acid III" is revised. 
Synthesis of methyl 3-acetoxy-2-methyl-4-0xopentanoate (IIb)

a) Methyl 3-acetoxy-2,4-dimethy 1-4-pentenoate (IIIb). In a $200 \mathrm{ml}$ three necked flask, equipped with a mechanical stirrer, a condenser and a dropping funnel were placed $30 \mathrm{ml}$ of dry benzene and $1 \mathrm{lg}$ of activated zinc. In the dropping funnel was placed a solution of $30 \mathrm{~g}$ of methyl $\alpha$-bromopropionate and $13 \mathrm{~g}$ of methacrolein in $50 \mathrm{ml}$ of dry benzene. Initially a few $\mathrm{ml}$ of the above solution and one piece of iodine were added to the flask with stirring. When exothermic reaction set in, the remainder of the solution was gradually added for $30 \mathrm{~min}$, and then flask was heated to maintain gentle boiling for additional $1 \mathrm{hr}$. The reaction mixture was cooled and treated with $50 \mathrm{ml}$ of $10 \%$ aqueous sulfuric acid. The aqueous layer was extracted with three $100 \mathrm{ml}$ portions of benzene. Combined extracts were evaporated under reduced pressure and the residue distilled. The yield of methyl 3-hydroxy-2,4-dimethyl-4-pentenoate (IIIa), bp $71 \sim 73^{\circ} \mathrm{C} / 1.2 \sim 1.5 \mathrm{~mm}$, was $12.5 \mathrm{~g}$.

To a solution of $12 \mathrm{~g}$ of IIIa in $20 \mathrm{ml}$ of dry pyridine was added $15 \mathrm{ml}$ of acetic anhydride. On standing at room temperature for $15 \mathrm{hr}$, the reaction mixture was poured into $100 \mathrm{ml}$ of $10 \%$ aqueous sulfuric acid. The aqueous layer was extracted with three $70 \mathrm{ml}$ portions of benzene and combined extracts were washed with $3 \%$ aqueous sodium bicarbonate solution. The benzene solution was evaporated under reduced pressure, and the residue distilled. Yield of pure methyl 3-acetoxy-2,4-dimethyl-4-pentenoate (IIIb), bp $87 \sim 89^{\circ} \mathrm{C} / 1.5 \mathrm{~mm}$, was $1 \mathrm{I} \mathrm{g}$. Anal. Found: C, 60.20; $\mathrm{H}, 8.13$. Calcd. for $\mathrm{C}_{10} \mathrm{H}_{16} \mathrm{O}_{2}: \mathrm{C}, 59.98$; $\mathrm{H}, 8.05 \%$. $\nu_{\max }^{\text {Film: }}: 3480,1740,1725,1260,1195,1170$, $1032,905 \mathrm{~cm}^{-1}$.

b) Methyl 3-acetoxy-2-methy 1-4-oxopentanoate (IIb). Ozone enriched oxygen stream was passed through a solution of $11 \mathrm{~g}$ of IIIb in $70 \mathrm{ml}$ of dry chloroform at $-15 \sim-20^{\circ} \mathrm{C}$ for $2 \mathrm{hr}$. At the end of the reaction, the solution turned pale blue. Chlorofrom was distilled under reduced pressure and the residual oil was boiled with $50 \mathrm{ml}$ of water for 30 min. After cooling, the aqueous solution was extracted with three $60 \mathrm{ml}$ portions of benzene, and the combined extracts were subjected to vaccum distillation. Methyl 3-acetoxy-2-methyl-4-oxopentanote (IIb) was collected at $87 \sim 90^{\circ} \mathrm{C} / 2 \mathrm{~mm}$ in an yield of $9.8 \mathrm{~g}$. Anal. Found: C, 54.07; H, 7.27. Calcd. for $\mathrm{C}_{9} \mathrm{H}_{14} \mathrm{O}_{5}$ : C, 53.46; H, 6.98\%. $\nu_{\max }^{\text {Film }} 1750$ (broad), 1250 (broad), $1063,1050,1026 \mathrm{~cm}^{-1}$ The NMR spectrum is shown in Fig. 1. It shows two peaks at retention times 10 and $11.2 \mathrm{~min}$ on gas-liquid chromatography.

\section{Catalytic hydrogenation of the natural IIa}

a) In acidic medium. Three hundred $\mathrm{mg}$ of the natural IIa was hydrogenated over $300 \mathrm{mg}$ of Adams' catalyst in acetic acid for $3 \mathrm{hr}$ until $42 \mathrm{ml}$ ( 1 molar equivalent) of hydrogen was absorbed. After removal of the catalyst, acetic acid was distilled off under reduced pressure. The residual syrup was dissolved in ethyl acetate, which was extracted with $3 \%$ aqueous bicarbonate solution. Evaporation of the ethyl acetate gave $110 \mathrm{mg}$ of crude lactone. The product was chromatographed on a silicic acid $(10 \mathrm{~g})$ column by the use of benzene-ethyl acetate $(100: 4)$ to give pure lactone (VI). $\nu_{\max }^{\text {Film }}: 1780,1750,1230$, $1180 \mathrm{~cm}^{-1} . \quad[\alpha]_{D}^{18}=+57^{\circ} \quad(c=2.1$, methanol $)$. The NMR spectrum is shown in Fig. 2. The sodium bicarbonate layer separated as mentioned above was acidified and the acidic solution was extracted with ethyl acetate. Evaporation of the solvent afforded $100 \mathrm{mg}$ of hydroxy acid (V). $\nu_{\max }^{\text {Film }}: 3500 \sim 2800$ (broad), $1750 \sim 1720$ (broad), $1245,1050 \mathrm{~m}^{-1}$.

b) In the neutral medium. Three hundred $\mathrm{mg}$ of the natural IIa was hydrogenated over $300 \mathrm{mg}$ of Adams' catalyst in methanol. It uptook 1 molar equivalent of hydrogen for $5 \mathrm{hr}$. The product was treated in the usual way to give $10 \mathrm{mg}$ of a neutral fraction together with $210 \mathrm{mg}$ of a mixture of hydroxy acids.

\section{Catalytic hydrogenation of the synthetic IIb}

Three hundred and forty $\mathrm{mg}$ of the synthetic IIb was subjected to catalytic hydrogenation over $200 \mathrm{mg}$ of Adams' catalyst in methanol. In the usual way, $310 \mathrm{mg}$ of neutral fraction was obtained, which showed absorption bands at 3440, 1776, 1745 (broad), $1230,1045 \mathrm{~cm}^{-1}$, suggesting the presence of a lactone and hydroxy esters. The product was purified through a silicic acid $(20 \mathrm{~g})$ column. Elution with benzene-ethyl acetate $(100: 4)$ afforded $35 \mathrm{mg}$ of oily lactone (VII). $\quad \nu_{\max }^{\text {Film }}: 1782,1745,1235,1180 \mathrm{~cm}^{-1}$. NMR spectrum: $3 \mathrm{H}, \mathrm{d}, \delta 1.33,3 \mathrm{H}, \mathrm{d}, \delta 1.47$; of $3 \mathrm{H}, \mathrm{s}$, $\delta 2.10 ; 1 \mathrm{H}, \mathrm{m}, \delta 2.72 ; 1 \mathrm{H}, \mathrm{m}, \delta 4.38 ; 1 \mathrm{H}, \mathrm{t}(\mathrm{d}-\mathrm{d})$, $\delta 4.82$. Further elution with benzene-ethyl acetate (100:10 and 100:20) gave a mixture of hydroxy esters but recovery from the column was low (60 $\mathrm{mg}$ ).

Preparation of 3,5-dinitrobenzoate of (t)-3methyl-2-pentanol from the natural IIb

a) 2-Methyl-1,3,4-pentanetriol (IX). To a solution of $2 \mathrm{~g}$ of lithium aluminum hydride in $30 \mathrm{ml}$ of tetrahydrofuran was added a solution of $3 \mathrm{~g}$ of the 
natural IIb in $10 \mathrm{ml}$ of tetrahydrofuran at $70 \sim 80^{\circ} \mathrm{C}$ and the reaction mixture was heated at $80^{\circ} \mathrm{C}$ for $7 \mathrm{hr}$. After cooling, small amounts of ethyl acetate and water were added. The precipitate were removed by filtration and washed successively with tetrahydrofuran and ethyl acetate several times. Combined solutions were evaporated under reduced pressure to give $2.2 \mathrm{~g}$ of oily crude triol (IX), which was purified through a silicic acid $(40 \mathrm{~g})$ column. Elution with benzene-ethyl acetate $(70: 25: 5)$ gave $300 \mathrm{mg}$ of 3 acetoxy-2-methyl-1,4-pentanediol. Further elution with benzene-ethyl acetate-acetone-methanol (70:20: $5: 5$ ) afforded $1.7 \mathrm{~g}$ of pure triol (IX). Anal. Found: C, 53.39; $\mathrm{H}, 10.53$. Calcd. for $\mathrm{C}_{6} \mathrm{H}_{14} \mathrm{O}_{3}: \mathrm{C}, 53.71 ; \mathrm{H}$, $10.52 \%$. $\nu_{\max }^{\text {Film }}: 3400$ (broad) $1040,990 \mathrm{~cm}^{-1}$

b) Dimethanesulfonate of $\mathbf{I X}(\mathbf{X})$. To a solution of $600 \mathrm{mg}$ of IX in $10 \mathrm{ml}$ of pyridine was added $1.24 \mathrm{~g}$ of methanesulfonyl chloride at $-5^{\circ} \mathrm{C}$. After standing at $5^{\circ} \mathrm{C}$ overnight, the reaction mixture was poured into $30 \mathrm{ml}$ of $10 \%$ aqueous sulfuric acid with stirring and aqueous layer was extracted with two $50 \mathrm{ml}$ portions of benzene and successively with two $50 \mathrm{ml}$ portions of ethyl acetate. Evaporation of the benzene solution gave $520 \mathrm{ml}$ of syrup, which was a mixture of di- and trimethanesulfonates. On evaporation of the ethyl acetate fraction, $360 \mathrm{mg}$ of dimethanesulfonate (X) was obtained. The mixture of di- and trimethanesulfonates was chromatographed on a silicic acid ( $22 \mathrm{~g})$ column. Elution with benzene-ethyl acetate (100:15) gave $130 \mathrm{mg}$ of crystalline trimethanesulfonate melting at $114.5^{\circ} \mathrm{C}$. Anal. Found: C, 29.72; $\mathrm{H}, 5.73 ; \mathrm{S}, 2603$. Calcd. for $\mathrm{C}_{9} \mathrm{H}_{20} \mathrm{O}_{9} \mathrm{~S}_{3}: \mathrm{C}, 29.33$; $\mathrm{H}, 5.47$; S, 26.11\%;. $\nu_{\max }^{\text {Nujol: }} 1340$ (broa), 1172, 1032, $980,930,860,770,721 \mathrm{~cm}^{-1}$. Elution with benzeneethyl acetate $(70: 30)$ afforded $136 \mathrm{mg}$ of $X$. The total yield of $\mathrm{X}$ was $500 \mathrm{mg}$. Anal. Found: C, 33.23; 6.23; S. 22.29. Calcd. for $\mathrm{C}_{8} \mathrm{H}_{18} \mathrm{O}_{7} \mathrm{~S}_{2}: \mathrm{C}, 33.09 ; \mathrm{H}$, 6.24 S. 22.09\%. $\nu_{\max }^{\text {Film }}: 3550,1350,1176,970$, $915 \mathrm{~cm}^{-1}$. c) 3,5-Dinitrobenzoate of (t)-2-methyl-3-pentanol (XI). Five hundred and sixty $\mathrm{mg}$ of $\mathrm{X}$ was reduced with $700 \mathrm{mg}$ of lithium aluminum hydride in boiling ether for $5 \mathrm{hr}$. The reaction mixture was treated with a small amount of water and the ether layer separated by centrifuge from the precipitate, which was washed with ether several times. Combined ether solutions were evaporated under atmospheric pressure to give a liquid alcoholic residue. The residue was dissolved in $10 \mathrm{ml}$ of pyridine and 250 $\mathrm{mg}$ of 3,5-dinitrobenzoyl chloride was added to the solution at $0^{\circ} \mathrm{C}$. On standing at $5^{\circ} \mathrm{C}$ for $24 \mathrm{hr}$, the reaction mixture was poured into cold $10 \%$ aqueous sulfuric acid. The aqueous layer was extracted with a benzene-ether mixture several times. Evaporation of the solvent gave $400 \mathrm{mg}$ of crude 3,5-dinitrobenzoate, which was purified through a silicic acid $(22 \mathrm{~g})$ column. Elution with benzene-hexane $(1: \mathrm{l})$ gave $150 \mathrm{mg}$ of pure ester of XI melting at $98 \sim 99^{\circ} \mathrm{C}$. $[\alpha]_{D}^{15}=+7.7^{\circ}(\mathrm{C}=2.9$, chloroform $)$. Anal. Found: $\mathrm{C}$, $53.09 ; \mathrm{H}, 5.52 ;$ N. 9.52. Calcd. for $\mathrm{C}_{13} \mathrm{H}_{16} \mathrm{~N}_{2} \mathrm{O}_{6}$ : C. $52.70 ; \mathrm{H}, 5.44 ; \mathrm{N}, 9.46 \% . \nu_{\max }^{\mathrm{Nuj}}: 3090,1730,1630$, $1548,1360,1290,1175,735,725 \mathrm{~cm}^{-1}$. NMR spectrum: $3 \mathrm{H}, \mathrm{t}, \delta 0.91 ; 6 \mathrm{H}, \mathrm{d}, \delta 1.00 ; 2 \mathrm{H}, \mathrm{m}, \delta 8.1 \sim 8.5$; $1 \mathrm{H}, \mathrm{m}, \delta 7.8 \sim 8.1 ; 1 \mathrm{H}, \mathrm{m}, \delta 5.0$.

Acknowledgement. The authors are indebted to Kaken Chemical Co. for the preparation of crude piericidin and Mr. Aizawa of this Department for measurement of IR, UV and NMR spectra. This research was supported in part by the research fund given to one of the authors (N.T.) from Waksman Foundation of Japan Inc., to which authors wish to express their thanks. 